\title{
Praktek Kuliah Lapangan/Kuliah Kerja Lapangan di Perguruan Tinggi (Survey Pendapat di UNJ dan UPI)
}

\author{
Aris Munandar', Enok Maryani' ${ }^{2}$, Dede Rohmat ${ }^{3}$, Mamat Ruhimat ${ }^{4}$ \\ ${ }^{1}$ Dosen FIS UNJ \\ ${ }^{2-4}$ Dosen Pasca Sarjana UPI \\ Email : amunandar@unj.ac.id
}

\begin{abstract}
This study aims to survey PKL / KKL activities for undergraduate student in some universities- The descriptive method has been applied to predict the similarities and differences in the implementation of PKL / KKL. Meanwhile, the survey will be used to observe the implementation of PKL / KKL. All students of the Geography undergraduate program FIS UNJ and UPI will act as the population and we will use the obervation by sampling technique. A preliminary survey to collect the data from PKL / KKL implementation has been done from five universities (UNJ, UPI, UNY, UNES, UNESA). According to the observation and results, it shows similarities and differences. The equation in naming, goals, amount of activities, mechanism, duration of implementation, selection of location, source of funding, data collection. Differences in aspects amount of system credit semester, supervisory ratios, products produced. Hence, we conclude this study is relevant to create a balanced product and process assessment, an instrument from pre-field activities, field implementation, and post-field implementation.
\end{abstract}

Keywords: Comparison, Praktek Kuliah Lapangan (PKL), Kuliah Kerja Lapangan (KKL),

\section{Abstrak}

Penelitian bertujuan untuk mensurvey kegiatan PKL/KKL di perguruan tinggi. Metode deskriptif untuk mencari persamaan dan perbedaan pelaksanaan PKL/KKL, sedangakn survey untuk menjaring pendapat tentang pelaksanaan PKL/KKL. Populasi penelitian semua mahasiswa program studi pendidikan Geografi FIS UNJ dan UPI. Sampel yang digunakan dengan 120 mahasiswa dengan teknik kuota sampling. Survey pendahuluan untuk menjaring data pelaksanaan PKL/KKL di lima perguruan tinggi (UNJ, UPI, UNY, UNES, UNESA). Setelah tersusun dokumen, disampaikan kemahasiswa apakah sudah cocok atau belum sesuai dengan kondisi dilapangan dan harapannya. Hasil penelusuran dan survey menunjukan persamaan dan perbedaan. Persamaan pada penamaan, tujuan, banyaknya kegiatan, mekanisme, lama pelaksanaan, penentuan lokasi, sumber pendanaan, pengumpulan data. Perbedaan pada aspek bebabn SKS, rasio dosen pembimbing, produk yang dihasilkan. Hasil dari penelitian ini disarankan membuat instrument penilaian proses dan produk yang seimbang dari pra kegiatan lapangan, pelaksanaan dilapangan dan pasca dilapangan. Masing-masing aspek penilaian diberikan bobot yang seimbang.

Kata Kunci : Kuliah Kerja Lapangan (KKL), Perbandingan, Praktek Kuliah Lapangan (PKL)

\section{PENDAHULUAN}

Peningkatan kualitas penduduk dapat diukur dengan menggunakan IPM (Indeks Pembangunan Manusia). Salah satu unsur ukuran kemajuan dalam menghitung IPM yaitu pendidikan. Pendidikan dilihat dari lama sekolah dan harapan sekolah. Lama mengenyam pendidikan mempengaruhi kualitas penduduk secara langsung. Semakin tinggi penduduk mengenyam pendidkan maka semakin tinggi kualitas manusia. Semakin banyak penduduk masuk dan menyelesaikan di pendidikan tinggi, semakin meningkatlah kualitas penduduk. 
Kualitas pendidikan dapat dilihat dari adanya peningkatan prestasi akademik atau hasil belajar dalam suatu satuan pendidikan. Satuan pendidikan tinggi merupakan jenjang pendidikan yang menghasilkan tenaga terampil sesuai dengan bidangnya. Perguruan tinggi seperti universitas, menghasilkan tenaga terampil yang siap dibidangnya. Tujuan pendidikan tinggi seperti yang tercantum dalam Undang-Undang No. 12 Tahun 2012 yaitu dihasilkan lulusan yang menguasai ilmu pengetahuan dan teknologi untuk memenuhi kepentingan nasional dan peningkatan daya saing bangsa.

Salah satu universitas yang menghasilkan tenaga dibidang pendidikan yaitu, universitas eks LPTK (Lembaga Penghasil Tenaga Kependidikan), yang outcame menjadi seorang pendidik. Sebagai salah satu progam studi/jurusan yaitu pendidikan Geografi. Penjabaran kompetensi lulusan pendidikan Geografi dapat dilihat dari kurikulum yang digunakan. Struktur kurikulum yang utama dilihat dari adalah pengajar, pembelajar dan assessment (Azim, 2012). Review kurikulum menjadi kunci strategis universitas dalam menjamin lulusannya dengan pembuktian profil assessment yang dapat menginformasikan

kebutuhan stakeholder (Bosco \& Ferns, 2014). Struktur kurikulum yang dapat dijabarkan dalam mata kuliah menjadi ciri khas program studi pendidikan geografi adalah kegiatan lapangan.

Kegiatan lapangan ini menjadi ciri khas dengan program studi lain karena Geografi memiliki kajian yang sangat dekat antara interaksi dengan lingkungan. Kegiatan lapangan ini sangat khas karena laboratoriumnya Geografi adalah alam itu sendiri. Kegiatan lapangan memiliki beberapa istilah salah satunya, fieldwork. Fieldwork adalah jantungnya geografi (Gold, et al. 1991). Fieldwork ini memiliki keunikan karena mahasiswa diwajibkan untuk turun terjun langsung mengamati fenomena sesuai dengan tema kajian. Mahasiswa dapat menerapkan teori yang ada di kelas untuk dipraktekan di lapangan. Fieldwork memberikan kesempatan untuk belajar tidak seperti tiruan di kelas, tetapi dapat meningkatkan pemahaman konsep dan kenampakan geografi serta mengembangkan keterampilan yang spesifik (HMI, 1992). Penelitian yang lain menghubungkan antara kegiatan lapangan dan dorongan belajar peserta didik yang memberikan 
keuntungan dalam pendididkan. Adanya hubungan yang efektif antara respon peserta didik dalam hal emosi perasaan dan nilai pembelajaran yang lebih mendalam ketika dilakukan kegiatan lapangan (fieldstudy) (Higgitt, 1996; Fuller, et al., 2006; Boyle, et al., 2007).

Pembelajaran PKL/KKL ini dibimbing oleh dosen yang akan membimbing sejumlah mahasiswa. Teknis pelaksanaan PKL/KKL dimulai dengan rapat panitia untuk menentukan lokasi, kemudian disetujui oleh pembimbing. Pemaparan lokasi oleh panitia, kemudian ditetapkan secara bersama dengan dosen pembimbing. Rangkaian yang panjang dari rapat-rapat panitia, persiapan, pelaksanaan, presentasi hasil laporan sampai pembuatan akhir laporan memerlukan suatu instrumen untuk penilaian. Berdasarkan hasil penelitian Mulyantari (2005), Kuliah Kerja Lapangan I Jurusan Geografi di Universitas Negeri Semarang menyimpulkan, kegiatan ini dapat dijadikan sebagai salah satu pembelajaran kontekstual, karena sudah memenuhi tujuh komponen dalam pembelajaran kontekstual, tetapi masih perlu ditingkatkan untuk komponen menemukan (inquiry) dan komponen penilaian sebenarnya (authentic assessment).

PKL/KKL seperti apakah yang dibutuhkan oleh mahasiswa sebagai bekal nantinya ketika sudah terjun ke masyarakat? PKL/KKL yang dapat digunakan sebagai tempat pembelajaran di lapangan dengan menghubungkan segala macam pengetahuan yang diperoleh di kelas untuk dapat dipraktikkan di luar kelas sehingga diperlukan pelaksanaan PKL/KKL yang benar-benar ideal. Berdasarkan masalah penelitian dan pertanyaan penelitian yang telah dirumuskan, maka fokus penelitian diarahkan pada studi perbandingan PKL/KKL di program studi/Jurusan Pendidikan Geografi di lima universitas (UNJ, UPI, UNY, UNESA, UNNES).

\section{METODE PENELITIAN}

Penelitian ini bertujuan untuk menjaring pendapat tentang pelaksanaan PKL/KKL. Dalam penelitian ini ada dua metode yang digunakan yaitu metode deskriptif dan survey. Metode deskriptif untuk penelitian pendahuluan dengan melihat kondisi yang ada, terkait dengan pelaksanaan PKL dan KKL. Survey dilakukan dengan menyampaikan hasil 
penelitian pendahuluan diminta tanggapan kepada peserta PKL/KKL.

Lokasi penelitian di program studi Pendidikan Geografi FIS UNJ dan UPI. Populasi penelitian semua mahasiswa program studi Pendidikan Geografi FIS UNJ, dan UPI yang mengikuti kegiatan PKL/KKL. Sampel dengan kuota sampling, populasi terbagi menjadi 6 kelompok masing-masing 20 peserta yang melaksanakan PKL/KKL di semester 2, 4, dan 6. Total sampel yang dijadikan responden 120 peserta.

Survei dilakukan setelah dokumen PKL/KKL diperoleh dari penelitian pendahuluan. Sumber data dalam penelitian ini data primer dan sekunder. Data sekunder berupa dokumen RPKSP/SAP, Buku pedoman akademik, SOP dan dokumen lainnya dari lima universitas. Survey pendapat diperoleh dari peserta PKL/KKL. Pengolahan dan analisis data hasil penelitian menggunakan teknik analisis deskriptif komparatif. Prosedur pengolahan dan analisis data dilakukan berdasarkan tahapan-tahapan sebagai berikut studi pendahuluan, pengembangan dokumen, survey pendapat.

\section{HASIL DAN PEMBAHASAN}

Penelusuran dokumen diperoleh dari Buku Pedoman Akademik, SOP (Standar Operasional Prosedur), hasil penelitian dan dokumen lainnya. Hasil penelusuran untuk mengetahui persamaan maupun perbedaan dari pelaksanaan kegiatan PKL/KKL pada masing-masing program studi. Aspek yang menjadi acuan penelusuran yaitu penamaan, definisi, banyaknya pelaksanaan, tujuan, beban SKS (Sistem Kredit Semester), mekanisme kegiatan, materi kajian, lama pelaksanaan, penentuan lokasi, perbandingan dosen pembimbing dengan mahasiswa, pendanaan, produk yang dihasilkan, penilaian, serta proses pengumpulan data.

Hasil survey pendahuluan adanya persamaan dan perbedaan dalam unsur pelaksanaan PKL/KKL. Persamaan pada penamaan, tujuan, banyaknya kegiatan, mekanisme, lama pelaksanaan, penentuan lokasi, sumber pendanaan dan pengumpulan data. Perbedaan pada aspek beban SKS, rasio dosen pembimbing, dan produk yang dihasilkan.

Persamaan dan perbedaan unsur tersebut ditanyakan kepada peserta PKL/KKL untuk mengetahui kecenderungan jawaban maupun harapan dari 
pelaksanaan kegiatan. Hasil dari survey digambarkan dalam grafik berikut : terhadap 120 peserta PKL/KKL dapat

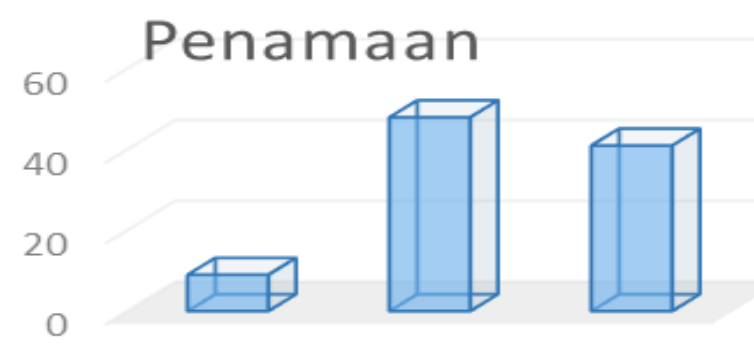

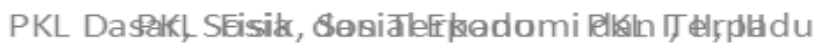

Gambar 1. Penamaan PKL/KKL

\section{BANYAKNYA}

100

$\mathrm{O}$

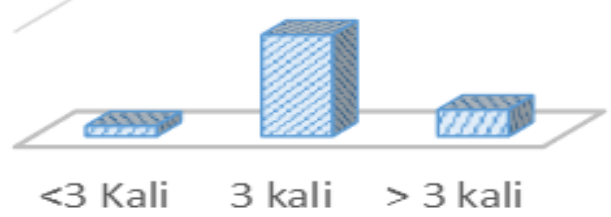

Gambar 2. Banyaknya PKL/KKL

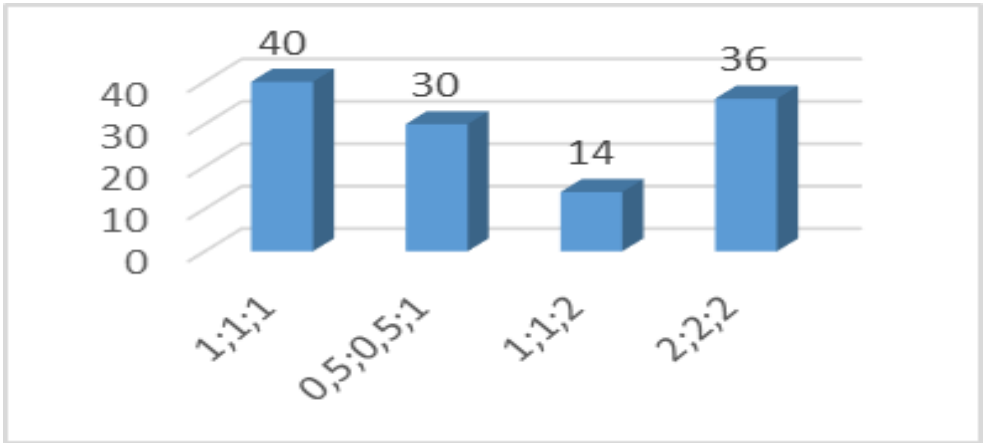

Gambar 3. SKS PKL/KKL

Tahapan Pra,Pelaksanaan dan Pasca

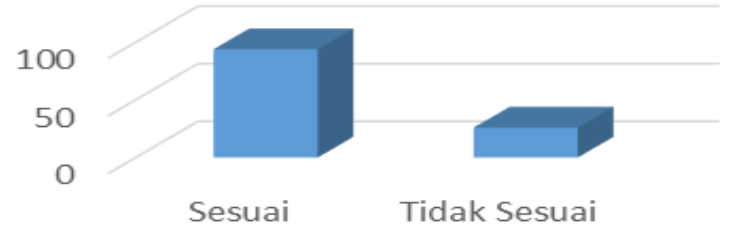

Gambar 4. Mekanisme PKL/KKL 


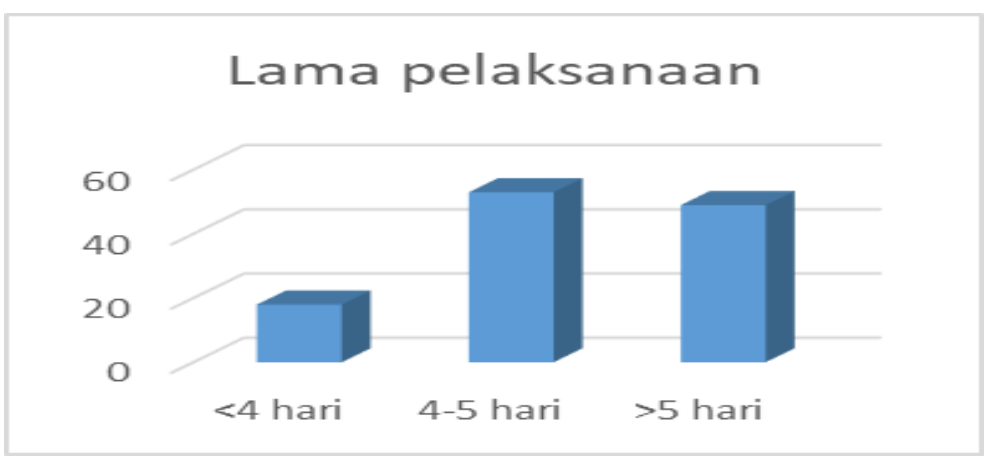

Gambar 5. Lama pelaksanaan PKL/KKL

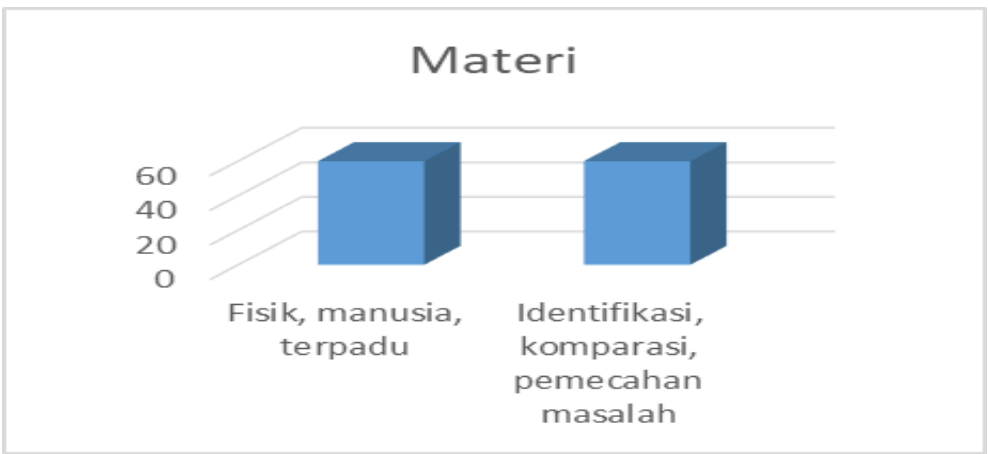

Gambar 6. Materi PKL/KKL

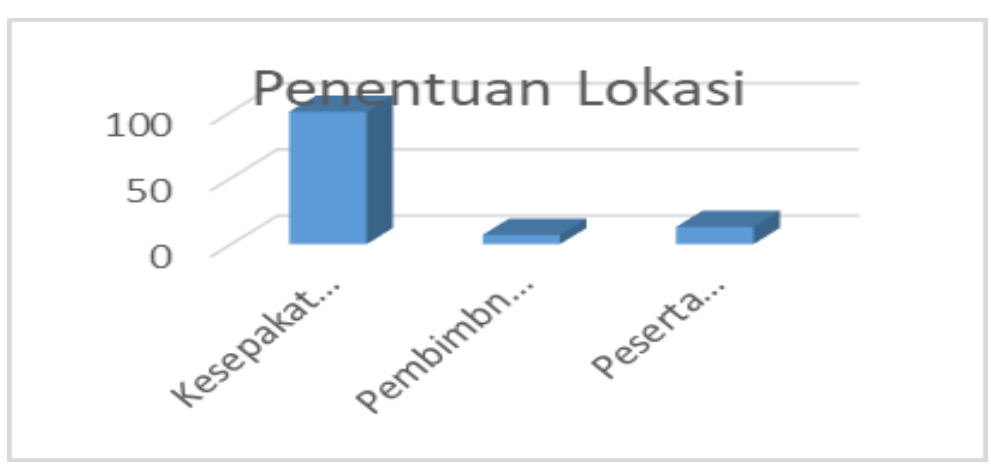

Gambar 7. Penentuan Lokasi

\section{Perbandingan pembimbing dengan peserta}

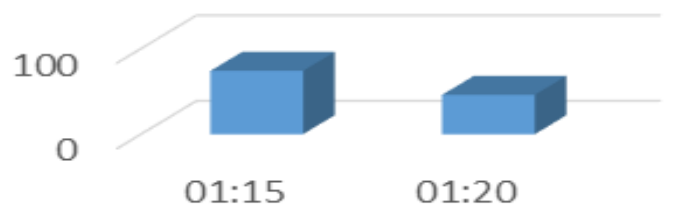

Gambar 8. Perbandingan Pembimbing dan Peserta 


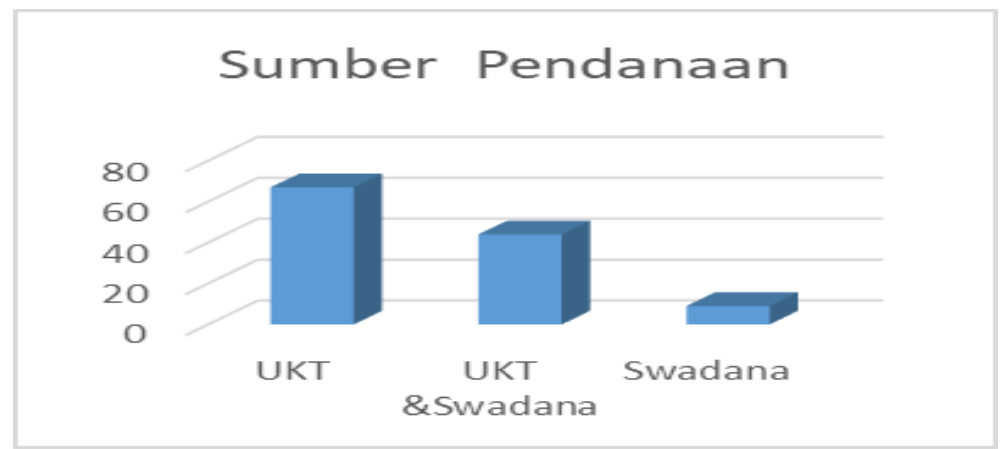

Gambar 9. Sumber pendanaan

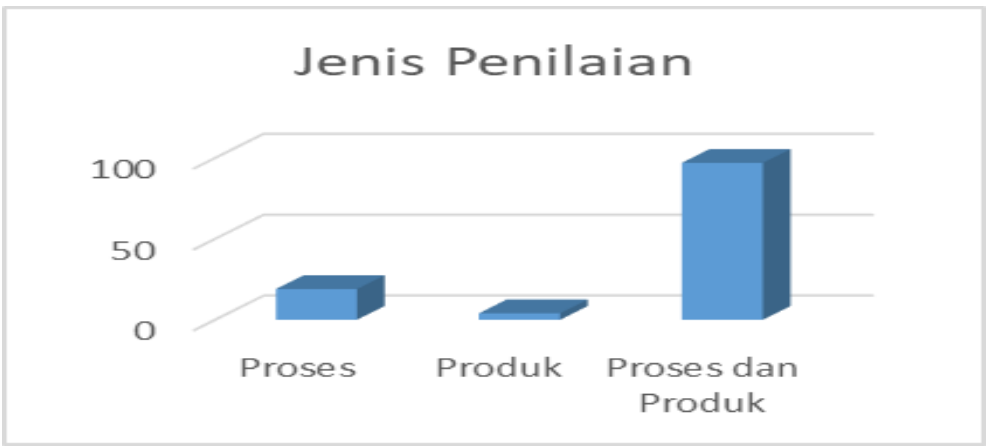

Gambar 10. Jenis penilaian

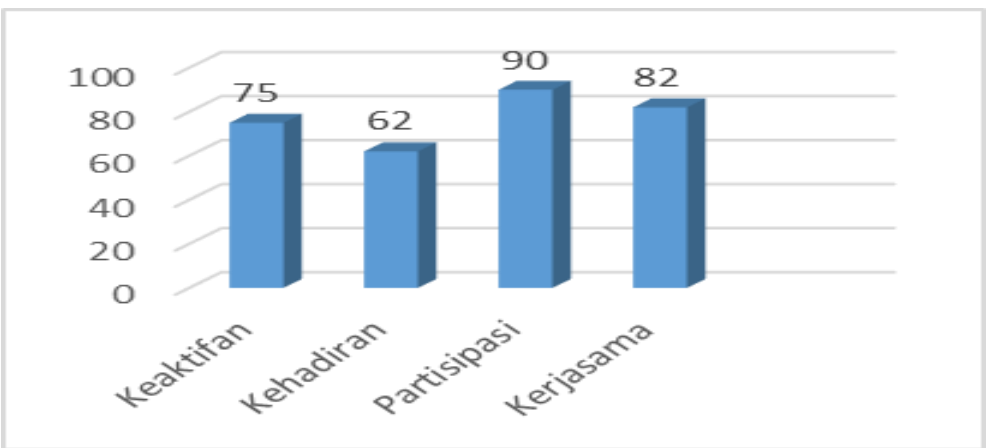

Gambar 11. Penilaian proses

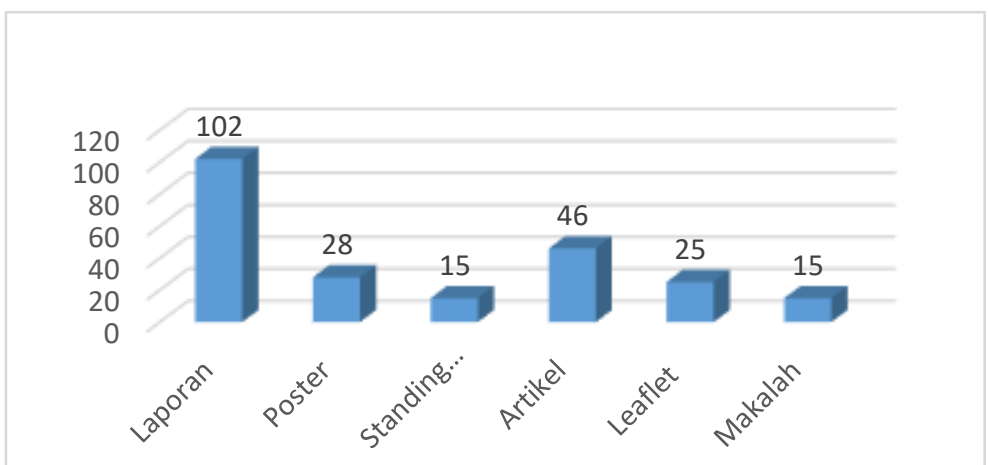

Gambar 12. Penilaian produk 


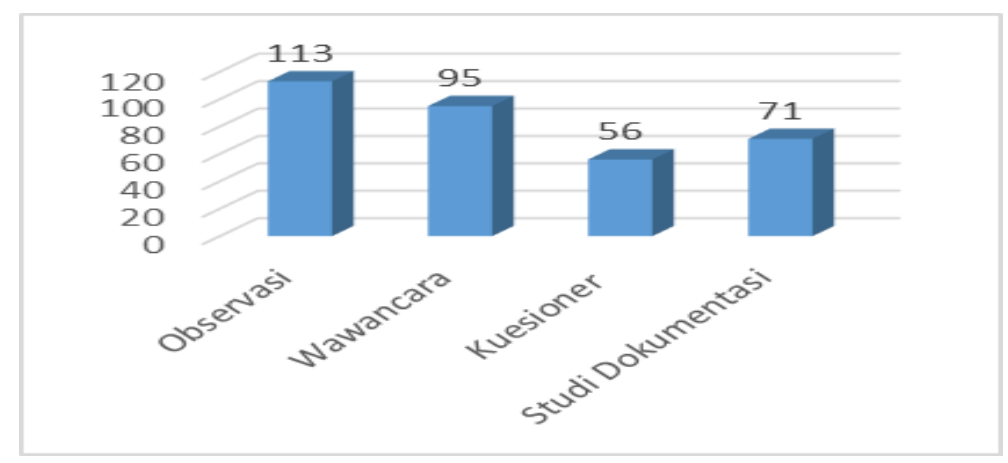

Gambar 13. Pengumpulan data

PEMBAHASAN

Penamaan kegiatan luar kelas beberapa universitas secara umum ada 2 yaitu PKL dan KKL. Penamaan KKL di UNESA, UPI dan UNNES, sedangkan penamaan PKL terdapat di UNJ dan UNY. Kegiatan lapangan di UNJ ada beberapa jenis yaitu PKL (Praktek Kuliah Lapangan), KKL (Kuliah Kerja Lapangan), Orientasi Lapangan, Praktek Industri. Perbedaaan disebabkan karakteristik disiplin ilmu di setiap fakultas (UNJ, 2016). Sebagai pembanding kegiatan yang serupa pada Ilmu Geografi di Fakultas Geografi Universitas Gajah Mada, kegiatan luar kelas dinamakan KKL, yang terbagi menjadi 3 kali KKL (UGM, 2010). Kegiatan luar kelas wajib bagi semua mahasiswa di Fakultas Geografi UGM. Kegiatan lapangan di FKIP Unila (Universitas Lampung) dinamakan KKL (Kuliah Kerja Lapangan) (PPPS FKIP Unila, 2015).
Hasil survey menunjukan responden hampir sama pilihan penamaan PKL fisik, sosial dan pemetaan serta terpadu dengan KKL I, II dan III. Jawaban paling banyak ini juga sesuai dengan lokasi pengambilan sampel. Karena survey dilakukan di UNJ dan UPI yang biasanya menyebutnya dengan penamaan tersebut. Demikian juga kemungkinan jika survey dilakukan di universitas yang lain, kecenderungan memilih jawaban penamaan yang sesuai dengan penyebutan yang sudah ada.

Secara umum, hasil survey di lima perguruan tinggi yang melakukan kegiatan luar lapangan memberikan nama yang memiliki ciri sama yaitu ada kata "lapangan" baik PKL dan KKL menggunakan kata "lapangan" untuk memberikan nama pada kegiatan luar kelas. "Lapangan" ini dalam istilah asing dengan "field". Kata "lapangan" ini merujuk pada kegiatan yang dilakukan di luar kelas/outdoor. Luar ruangan/kelas 
sebagai tempat aktivitas/kuliah dalam pembelajaran.

Banyaknya kegiatan lapangan di kelima universitas memiliki kesamaan yaitu sebanyak 3 kali yang dilakukan secara berurutan/perekuisit. Hasil survey pun menunjukan frekuensi PKL/KKL sebanyak 3 kali. Banyaknya PKL/KKL menunjukan pentingnya kelapangan dalam pembelajaran untuk memberikan pengalaman langsung kepada peserta. Pembelajaran tidak hanya dalam ruangan/indoor, tetapi membawa peserta keluar memberikan pengalaman langsung yang melibatkan lebih banyak panca indera dalam pembelajaran. Selain kegiatan lapangan dalam bentuk PKL/KKL beberapa mata kuliah melakukan kegiatan outdoor seperti fieldtrip, ekskursi, kunjungan atau kegiatan lainnya. Sebagai pembanding kegiatan yang serupa pada Ilmu Geografi, kegiatan luar kelas di FKIP Unila dilakukan 2 kali dengan nama KKL (Kuliah Kerja Lapangan) (PPPS FKIP Unila, 2015). Di Inggris, kegiatan yang hampir sama juga dilakukan yaitu fieldwork untuk kelompok usia 13-15 tahun (50-70\%), usia 17-18 (80\%). Sekolah di Inggris 3 kali lebih banyak dalam kegiatan lapangan dibandingkan di Brazil, menunjukan adanya kesenjangan negara maju dan berkembang (Lai \& Lam, 2013). Pelaksanaan kegiatan luar lapangan di negara maju lebih banyak daripada di negara berkembang.

Jumlah total SKS pelaksanaan kegiatan lapangan beragam dari 2 SKS (UPI), 3 SKS (UNY, UNNES) dan 4 SKS (UNJ) 6 SKS (UNESA). Hasil survey menunjukan beban SKS KKL 1, 2, 3 masing-masing dengan jawaban 1:1:1. Beragamnya beban SKS dipengaruhi oleh banyak faktor: waktu pelaksanaan, tugas yang harus dikumpulkan, dan jumlah pertemuan/tatap muka di kelas. Kegiatan lapangan membutuhkan alokasi waktu dari pra kegiatan, kegiatan dan pasca kegiatan. Pelaksanaan kegiatan lapangan membutuhkan persiapan yang matang, sehingga perlu ada kegiatan awal, untuk mengecek, mempersiapkan segala sesuatu agar kegiatan berjalan lancar. Prakegiatan dan pasca kegiatan biasanya dilakukan didalam kelas. Prakegiatan dalam bentuk tatap muka dikelas/presentasi lokasi awal oleh team advance, persiapan teknis dan nonteknis. Sehingga setiap universitas memiliki pembobotan yang berbeda untuk kegiatan PKL/KKL ini. 
Pembobotan sudah ada dalam struktur kurikulum masing-masing program studi ditiap universitas. Penentuan SKS dalam PKL/KKL harus mengacu pada Permenristekdikti No.44 Tahun 2015: pasal 15. Satu SKS setara dengan seratus tujuh puluh menit kegiatan belajar perminggu persemester (setara dengan 2,83 jam perminggu atau dibulatkan 3 jam). Penentuan SKS PKL/KKL yang terdiri dari kegiatan tatap muka dikelas, kegiatan di lapangan dan presentasi laporan dalam bentuk seminar. PKL/KKL dengan bobot 1 SKS pelaksanan di lapangan 5 hari setara dengan 13 pertemuan, sehingga tatap muka di kelas 2 kali@50 menit dan 1 seminar 100 menit. Kelompok PKL/KKL yang memiliki bobot 2 SKS menyesuaikan. Kegiatan PKL/KKL harus menyesuaikan beban SKS dengan banyaknya kegiatan tatap muka, seminar dan kegiatan praktik sesuai dengan aturan.

Pelaksanaan PKL/KKL dilakukan tergantung pada beban SKS, tetapi ratarata pada setiap perguruan tinggi, lama pelaksanaan selama 4-5 hari. Hasil survey menunjukan lama pelaksanaan PKL/KKL 4-5 hari. Pelaksanaan dilapangan meliputi pelepasan dari masing-masing program studi, perjalanan menuju lokasi, kajian dilapangan, perjalanan pulang kembali ke program studi masing-masing. Perjalanan menuju lokasi tergantung moda yang digunakan baik darat, laut maupun udara. Perjalanan darat menurut IAAM (2013), mahasiswa sudah dianggap senior pupils sehingga jaraknya dapat 5-15 miles (8-24 km) bahkan lebih. Lama pelaksanaan PKL/KKL di beberapa program studi universitas di Indonesia dibanding dengan kegiatan fieldstudy dibeberapa universitas di Asia Tenggara, sangat variatif tergantung pada jenjang dan tugas. Rata-rata seminggu untuk pelaksanaan kegiatan fieldstudy di beberapa universitas Asia Tenggara (Gerber \& Chuan, 2000). Pelaksanaan kegiatan field camp (6-7 minggu) field trip (0,5-1 hari) (Munandar, dkk., 2019). Waktu lebih lama lebih efektif daripada waktu singkat dalam pengaruh sikap kelingkungan.

Penentuan lokasi adanya kesepakatan bersama antara dosen pembimbing dengan peserta. hasil survey menunjukan jawaban penentuan lokasi PKL/KKL harus ditentukan bersama. Lokasi yang unik yang memiliki karakteristik tertentu sesuai dengan tujuan dan jenjang. Menurut 
Tilbury \& Williams (1997) untuk penentuan lokasi PKL/KKL, apabila lokasi diluar kota ataupun dalam negara memiliki karakteristik: kegiatan dilakukan dalam beberapa hari/menginap, adanya beberapa tugas yang harus diselesaikan, memiliki biaya transportasi yang tinggi, memiliki karakteristik wilayah yang unik atau berbeda. Lokasi yang eksotik dan mahal belum tentu sesuai dengan tujuan kegiatan (Lewis, 1968). Mengunjungi banyak lokasi dengan waktu singkat juga dihindari, agar ada interval antara untuk istirahat, relaksasi dan refleksi (Lai, 1999). Mengunjungi lokasi heritage dapat meningkatkan kepekaan terhadap peninggalan bersejarah (Munandar, dkk., 2019). Pembimbing harus menjamin adanya novelty bagi peserta di lokasi yang dipilih (Burnett, 1996). Pemilihan lokasi yang sama memiliki kelebihan dan kekurangan. Kelebihannya persiapan lebih baik, dapat mengetahui perkembangan dalam kurun waktu tertentu, wilayah sudah dikuasai pembimbing. Kelemahannya pembimbing merasa bosan dan kurang motivasi (Hart, 1968).

Perbandingan dosen pembimbing PKL/KKL dengan jumlah mahasiswa bervariasi seperti untuk program studi pendidikan geografi di UPI dan UNY perbandingannya $1: 15$, sedangkan di UNJ 1:20 sedangkan di UNESA, UNNES data tidak diperoleh. Hasil survey menunjukan separuh memilih 1:15 dan separuh memilih 1:20. Menurut IAAM (2014, hlm.214) untuk kegiatan lapangan diperlukan pembimbing dengan peserta dengan rasio1: 20. Apabila dibawah 1: 20 cukup ideal untuk kegiatan di luar. Kegiatan lapangan dengan membimbing 30-40, terlalu besar idealnya rasio 10-20 (Lai, 1999). Field camp atau field course rasio peserta dengan pembimbing 1: 10 (Hart, 1986). Seperti yang dikemukakan oleh Morgan, semakin rendah tingkat/kelas peserta dibutuhkan semakin banyak pembimbing. Kelas 2 sekolah dasar, 1 orang dewasa berbanding 5 peserta (1: 5). Kelas 3-12, 1 orang dewasa mendampingi 10 peserta (1:10). Kelompok kecil di dalam ruangan 1:7, sedangkan untuk diluar ruangan 1: 10 peserta siswa sekolah dasar (Gutwill, 2011).

Pendanaan merupakan faktor yang penting dalam kegiatan PKL/KKL. Pendanaan menyangkut transportasi kelokasi kajian, makan dan minum peserta, biaya menginap di suatu lokasi. Besarnya pengeluaran transportasi 
tergantung pada keterjangkauan lokasi, apakah menggunakan moda angkutan darat/laut/udara. Biaya hidup antar lokasi juga berbeda, yang perlu dipertimbangkan diawal kegiatan. Hasil survey menunjukan PKL/KKL didanai oleh institusi yang bersumber dariUKT (Uang Kuliah Tunggal), dimana pembayaran yang dilakukan sama/flat setiap semester menjadi kendala dalam pelaksanaan kegiatan keluar kelas. Keterbatasan UKT menutupi pembelajaran yang dilakukan diluar kelas. Beberapa perguruan tinggi tidak memungut untuk kegiatan PKL/KKL, beberapa lagi memungut dan sisanya bersifat subsidi. Bagi yang tidak memungut jumlah dana yang disediakan terbatas sehingga sangat berpengaruh terhadap penentuan lokasi. Pemilihan lokasi dibatasi dengan ketersediannya dana, sehinga sangat terbatas obyek kajiannya. Jika akan memilih obyek yang jauh harus menambah sendiri/swadana untuk menambah kekurangan dari dana yang disediakan. Bagi pelaksanaan kegiatan yang swadana tidak mengalami kesulitan ketika akan menentukan lokasi. Bervariasinya pendanaan baik yang penuh maupun subsidi tergantung pada kebijakan masing-masing wilayah (IAAM, 2013, hlm 236).

Beberapa yang dapat dilakukan untuk menutupi kegiatan yang besar, biasanya peserta melakukan usaha jauhjauh sebelum pelaksanaan. Kegiatan ketika ada even-even tertentu (wisuda, seminar dan lain-lain), peserta memanfaatkan untuk kegiatan berdagang. Hasil keuntungannya dapat dimanfaatkan untuk menutupi kekurangan dana PKL/KKL.

Hasil survey menunjukan penilaian dilakukan baik proses maupun produk. Pentingnya penilaian kedua tersebut karena mekanisme PKL/KKL dari perencanaan sampai pasca kegiatan. Penilaian proses dari aspek kerjasama selama kegiatan. Penilaian produk yang paling banyak menurut survey yaitu laporan. Penilaian sangat beragam, tetapi jika dilihat dari aspek mekanisme pelaksanaan terdapat kesamaan dan perbedaan dimasing-masing universitas. Penilaian pada pra kegiatan berupa perencanaan/pembekalan (yang menuntut adanya partisipasi/kehadiran, keaktifan, disiplinan, kerjasama), pelaksanaan (menuntut adanya keaktifan dan partisipasinya), dan pasca pelaksanaan dilapangan berupa laporan dan presentasi/ekspose. Perbedaan 
penilaian pada jenis aktivitas/produk yang dihasilkan berupa artikel, leaflet, makalah (Jurusan Geografi UPI). Pentingnya presentasi/ekspose berupa seminar sebagai variasi, intensitas, pencerahan, laporan dan penyampaian ide (Salisbury, 1968).

Hasil dari aktivitas PKL/KKL diakumulasikan untuk dikonsversikan kedalam nilai akhir. Studi pendahuluan tidak menemukan semua dokumen yang berkaitan dengan proses penghitungan atau konversi tagihan dalam PKL/KKL yang diberikan bobot untuk masingmasing aktivitas atau produk. Sebagai contoh di Departemen pendidikan UPI, adanya pembobotan laporan (42\%) kinerja/performa (42\%), baner (6\%). Pemberian bobotpun tidak sama yaitu antara universitas. Sehingga perlu dibuat rumusan pembobotan antara aktivitas/produk yang dihasilkan. Hasil pembobotan tersebut kemudian dikonversikan dengan penilaian akhir. Penelitian tentang pembobotan hasil dari kegiatan lapangan dapat ditemukan dalam perencanaan $(10 \%)$, pengumpulan data $(20 \%)$, analisis $(30 \%)$, interpretasi (30\%) dan evaluasi (10\%) (Lai. 2013, hlm 37).

Menurut Tilbury \& Williams (1997) setelah kegiatan lapangan perlu dilakukan evaluasi terhadap pelaksanaan dengan selang waktu 2 minggu. Perlunya evaluasi kegiatan untuk melihat sejauh mana keberhasilan program dengan tujuan. Mengetahui hambatan dan kendala dalam pelaksanaan dilapangan. Penilaian juga terhadap produk/tugas yang diberikan kepada peserta. Proses penilaian disini dimaksudkan untuk memberikan ukuran keberhasilan program baik dari segi proses maupun produk. Penilaian produk dapat berupa hasil laporan, lembar pengamatan dan lain-lain, sehingga dapat dilakukan pemberian nilai/angka kepada peserta kegiatan.

Pengumpulan data lapangan untuk kelima program studi/jurusan memiliki kesamaan baik data primer maupun sekunder. Pengumpulan data dapat dilakukan melalui : observasi, wawancara, kuesioner, studi dokumentasi. Pembuatan instrument PKL/KKL sangat penting agar dapat diperoleh data yang sesuai dengan tujuan kegiatan. Data sekunder sangat diperlukan sebagai data awal untuk melakukan pemetaan terhadap keadaan fisik dan sosial daerah kajian. Sumber data sekunder dapat diperoleh dari BPS (Badan Pusat Statistik) daerah atau website yang tersedia. Data primer 
dengan observasi, wawancara baik obyek fisik maupun sosial. Hasil survey menunjukan data primer obervasi lebih banyak dijawab. Observasi dilakukan ketika dilapangan untuk mempelajari fenomena fisik maupun beberapa fenomena sosial. Observasi sebagai cara yang tepat untuk perolehan data lapangan (Yilmaz, 2011). Observasi dilakukan ketika di lapangan untuk mempelajari fenomena fisik maupun fenomena sosial. Observasi dengan bantuan daftar isian, peserta dapat mencatat, megumpulkan data-data yang diperlukan untuk dapat dianalisis. Observasi mengamati fenomena fisik seperti mencatat susunan lapisan tanah, batuan, jenis batuan dan lain sebagainya. Observasi fenomena sosial seperti pengamatan aktivitas mata pencaharian, perilaku penduduk pada saat kegiatan sosial budaya maupun keagamaan. Kesulitan peserta dalam wawancara karena berbagai kendala seperti bahasa, tidak berada dilokasi. (Arianta, 2016). Data hasil observasi akan memperkaya data sekunder lainnya. Pengumpulan data dalam field ada 3 yaitu observasi, wawancara, recording (termasuk pemetaan) (Hart, 1968, hlm 32). Sumber data diperoleh dari observasi lapangan, arsip/dokumen (termasuk peta), theoretical work (Corey, 1968). Melalui fieldwork keterampilan observasi akan meningkat (Ofsted, 2011).

\section{PENUTUP}

Hasil penelusuran dokumen di lima universitas dan hasil survey menunjukan adanya persamaan dan perbedaan. Penamaan kegiatan lapangan hampir sama yaitu PKL Fisik/dasar, sosial dan terpadu. UPI dan UNESA menamai KKL I, II dan III. Banyaknya PKL/KKL 3 kali. Tujuan PKL/KKL cenderung sama. Mekanisme kegiatan cenderung sama pra, kegiatan dan pasca lapangan. Lama pelaksanaan antara 4-5 hari. Penentuan lokasi PKL/KKL cenderung sama ditentukan oleh dosen dan mahasiswa. Penilaian proses dan produk memiliki kecenderungan yang sama. Penjaringan data hampir sama melalui observasi, kuesioner, wawancara, studi dokumentasi. Sistematika laporan cenderung sama 5 bab. Perbedaan pada aspek beban SKS yang bervariasi antar 5 universitas dari 2 SKS- 4 SKS. Pada UPI penamaan yang berbeda sehingga materi kajian juga berbeda, bukan pada aspek konten tetapi proses. Rasio dosen pembimbing dengan pesertapun bervariasi antara 1:15 dengan 1:20. Produk yang dihasilkanpun 
bervariasi berupa laporan, artikel, leaflet, standing baner, makalah, brosur. Hasil dari penelitian dapat disarankan membuat instrument penilaian proses dan produk yang seimbang dari pra kegiatan-kegiatan dan pasca kegiatan serta memberikan bobot untuk masingmasing aspek penilaian baik proses dan produk.

\section{DAFTAR PUSTAKA}

Bosco, A.M. \& Ferns, S. (2014). Embedding of authentic assessment in work-integrated learning curriculum. Asia-Pacific Journal of Cooperative Education, 15(4), 281-290.

https://files.eric.ed.gov/fulltext/EJ1 113553.pdf

Azim, S., Khan, M. (2012). Authentic assessment: An instructional tool to enhance students learning. Academic Research International, 2(3), 314-320.

https://core.ac.uk/download/pdf/47 254979.pdf

Bahry, D.L., (1995). Crossing border:

The practice of comparative research. in Jarol B. Manheim and Richard C. Rich, Empirical political analysis: Research methods in political science, London, Longman Publisher.

Gerber, R. \& Chuan, G.K. (2000). Fieldwork in Geography: Reflection, perspectives and actions. Springer: Science Bussiness Media B.V

Gold. J. R., Jenkins, A., Lee, R. Monk. J., Riley. J., Shepherd, I.D.H. \& Unwin, D. J. (1991) Teaching Geography in higher education. Oxford: Blackwell.

Herrmann, R.K. (2002). Linking theory to evidence in international relations. in Walter Carlsnaes, Thomas Risse and Beth A. Simmons, Handbook of international relations. London: SAGE Publication.

Higgitt, M. (1996) Addressing the new agenda for fieldwork in higher education. Journal of Geography in Higher Education, 20(3), 391398.

HMI (Her Majesty's Inspectorate). (1992) A Survey of Geography fieldwork in degree Courses. Summer 1990 - Summer 1991. Sranmore: Her Majesty Inspectorate. Department of Education and Science. 
IAAM (The Incorporated Association of Asisstant Masters). (2013). The teaching of Geography in secondary schools. Cambridge University Press.

Fuller, I., Edmondson, S., France, D., Higgit, D. \& Ratinen, I. (2006). International perspectives on the effectiveness of Geography fieldwork for learning. Taylor \& Francis Journal of Geography in Higher Education, 30, 89-101.

Lai, C.K. (1999) Freedom to learn: A study of the experiences of secondary school teachers and students in a Geography field trip. International Research in Geographical and Environmental Education, 8(3), 239-255, DOI: $10.1080 / 10382049908667614$

Lai, K. C., \& Lam. C. C. (2013). Schoolbased assessment of fieldwork in Hong Kong: Dilemmas and challenges. Geography, 98(1), 3340.

Lewis, P. F. (1968). On field trips in Geography, in: Association of American Geographers (Ed.) Field training in Geography, Technical Paper 1, Commission on College Geography. Washington, DC:
Association of American Geographers.

Lijphart, A. (1975). The Comparablecases strategy in comparative research, dalam Comparative Political Studies. 8(2), 158 - 177, Sage Publications Inc.

McClelland, C.A. (1967). "Action Structure and Communication in Two International Crises: Quemoy and Berlin” dalam James Rosenau, International Politics and Foreign Policy: A reader in research and theory. New York: Free Press of Glencoe, Inc., pp 473-482.

Mulyantari, S. 2005 "Kuliah Kerja Lapangan (KKL) I Geografi sebagai salah satu metode pembelajaran kontekstual dan pengaruhnya terhadap prestasi belajar mahasiswa Pendidikan Geografi“. Jurusan Geografi. FIS. UNNES

Munandar, A., dkk. (2019). Fieldstudy dalam Geografi. Ponorogo: Uwais Inspirasi Indonesia.

Neil Labo, N. (2007). An assignment for the 'Issues of Concern in Geographic Education' Module. Student Journals and a Geography Field trip in Costarica 
Ragin, C.C. (1987). Comparative social science. dalam The comparative method: Moving beyond qualitative and quantitative strategies, 2(3), 314-320. London: University of California Press.

Tilbury, D. \& Williams, M. (1997). Teaching and learning Geography. London: Routledge.
UNJ. (2012). Pengembangan kurikulum program studi Pendidikan Geografi. Fakultas Ilmu Sosial.

UNJ. (2015). Buku pedoman akademik UNJ. Jakarta 